\title{
COMENTARIO
}

\section{Ética y reflexividad en antropología}

\author{
Andrew Roth-Seneff
}

$\mathrm{N}$

o he leído suficiente y menos críticamente asimilado las enseñanzas de Kant, Hegel, Wittgenstein o Rawls. Tampoco los desarrollos, derivaciones, aplicaciones y cuestionamientos de sus argumentos en las obras de Searle, Khun, Edel, Putnam y Díaz Polanco. Ni siquiera en el nivel de las ideas de los pensadores de la economía política, como los dos Mills, soy competente para precisar o deconstruir la naturaleza de sus orientaciones liberales frente a otras corrientes de liberalismo. Entonces antes de ofrecer una reflexión sobre ética y antropología a partir de la lectura de este provocante número de Desacatos pido una dispensa: no me es posible realizar un comentario filosóficamente correcto. Al referirme a lo filosóficamente correcto no quiero comunicar "algo" semejante a los hechos y dichos políticamente correctos. No se trata de una norma de representación correcta, sino del problema reflexivo de la objetivación. Mi conocimiento de Kant, de Hegel o de Wittgenstein no es adecuado para tratar este problema en sus obras o a partir de sus obras, pero en la antropología, en particular en el trabajo etnográfico, compartimos el problema de la objetivación y reflexivamente la objetivación de la pretensión a la objetivación; además, lo compartimos como un problema científico y también como un problema ético. De ahí que mi reflexión sea sobre este problema en la antropología.

Primero, la profesionalización e institucionalización de la antropología y su estrecha relación con el Occidente y la Ilustración son todavía demasiado relevantes. Tenemos un legado occidental probablemente más difícil de tornarse en el objeto crítico de reflexión que, por ejemplo, las posibles nociones de jerarquías de estatus o de género que Geertz supuso que están inscritas en el discurso correcto del javanés o el árabe marroquí (Sánchez Durá, en este volumen; Jacorzynski, en este volumen). Es aun más complejo cómo este legado contiene dos orientaciones enfrentadas con implicaciones metodológicas, y por tanto éticas, significativas. Como Hermann Rebel (2004: 160-182) ha señalado, existe en el Occidente una división filosófica-política-científica entre uno de los movimientos teológicos-filosóficos modernos tempranos - el nominalismo- y otra corriente teológica-filosófica desarrollada como

\section{Ethics and Reflexivity in Anthropology}

Andrew Roth-Seneff: El Colegio de Michoacán, Zamora, Michoacán, México aroth@colmich.edu.mx

Desacatos, núm. 41, enero-abril 2013, pp. 99-103 
reacción crítica al nominalismo - el realismo-. Entre los escolásticos el realismo se refiere a una postura que trata las categorías como universales y anteriores a la existencia de las cosas. El realismo se desarrolló como reacción al nominalismo, una postura en la que las ideas, los conceptos o las categorías son contemplados como emergentes de la experiencia humana, dentro de una realidad continua y heterogénea. En el realismo los conceptos son reales, tan reales como, o más, que las "cosas" sensibles; en el nominalismo los conceptos y las categorías son construcciones históricas derivadas de la experiencia.

Este legado occidental del realismo y el nominalismo es históricamente relevante para la discusión de la ética y la antropología, en especial si tal discusión toma como su enfoque las relaciones entre relativismo cultural y etnocentrismo. En la evaluación de una postura de relativismo es importante preguntarse si se trata de un relativismo absoluto o limitado-moderado y, en este último caso, cuáles que lo que moderará el relativismo en el realismo es diferente de lo que moderará en el nominalismo. En el realismo las categorías o los conceptos que subyacen a la experiencia y la práctica humanas deben moderar el relativismo. Como consecuencia, la cultura puede ser estudiada e interpretada como un producto - por ejemplo, un ensamble de textos o un guión construidos a partir de categorías o conceptos-, no como una producción (Roseberry, 1989: 20-29). Por tanto, el relativismo cultural está limitado por tales inscripciones y sus conceptos o categorías subyacentes. En contraste, si consideramos la "cultura" como una producción siempre ubicada en tiempo histórico y espacio social, los límites del relativismo se hacen más complejos. Los conceptos y categorías, también los textos, se construyen en tiempo y espacio, por lo que el balance entre la hermenéutica y la historia en el quehacer antropológico también cambia. El contexto histórico cobra mayor importancia para la interpretación, puesto que desde el nominalismo la práctica precede

a las reglas y los parámetros comunes de la práctica humana se postulan como los factores que moderan el relativismo (Bourdieu, 1977: 22-30).

En los ensayos de Sánchez Durá y Sánchez Jiménez y en las revisiones críticas de estos ensayos de Jacorzynski y Ordiano Hernández, respectivamente, queda clara una postura más pragmática y nominalista asociada con Wittgenstein en su periodo tardío. Menos claro es, sin embargo, el uso de la postura de Geertz respecto de la cultura. Rebel (2004: 176) argumenta que la postura de Geertz, siguiendo a Gilbert Ryle, proviene del realismo, y en su práctica la cultura es a menudo tratada como un producto. En la obra de Sánchez Durá existe cierta tensión en la tipología de orientaciones etnocéntricas: ¿en qué consiste la base o el fundamento de estas generalizaciones tan informadas por las ideas de Geertz acerca de la cultura? ¿Son generalizaciones sobre procesos culturales relacionados por categorías o conceptos comunes? O al contrario: ¿son generalizaciones o tipificaciones en una historia cultural de cómo ciertas corrientes de pensamiento occidental han elaborado estas relaciones a partir de un relativismo cultural moderado por supuestos realistas y etnocéntricos?

Wittgenstein, en sus "Reflexiones acerca de la Rama dorada de Frazer", es claro en su crítica no sólo del etnocentrismo, sino de la naturaleza histórica de éste (Wittgenstein, 1993, citado en Bourdieu, 2003). Para Wittgenstein, Frazer había enajenado su propio pensamiento reflexivo por razones históricas de crianza, tradición y educación formal. En lugar de una reflexividad que incluía su propia pretensión de objetivar las objetivaciones de otros, Frazer objetivaba las prácticas de otros, de manera que justificaba una ubicación narrativamente oculta en el espacio social y en el tiempo histórico de un imperio. Esto es etnocentrismo pero desde un realismo del imperio difícil de vislumbrar (Roth-Seneff, 2007). Esta lectura de la crítica de Wittgenstein a una obra de Frazer no es mía, proviene de Bourdieu (2003: 281-294), quien al final de su vida publicó varios trabajos metodológicos que subrayan con 


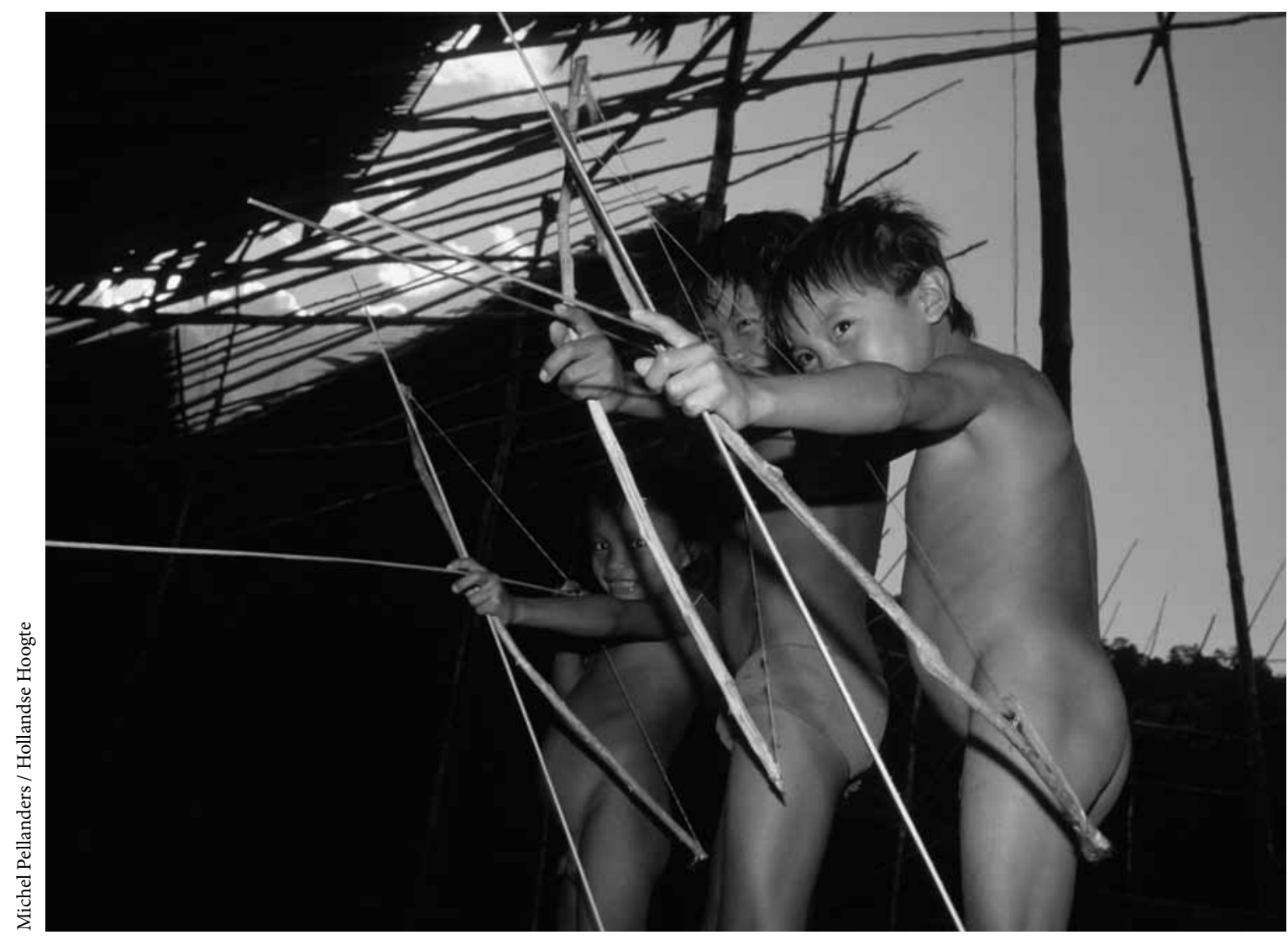

Niños yanomami practican con arco y flecha en la maloca. Demini, Roraima, Brasil, 1989.

claridad que en antropología, por su naturaleza, la ética nunca debe separarse de la metodología (Bourdieu, 2000, 2003 y 2004). La antropología, como una disciplina científica y no como un género literario, trabaja con informantes a partir de un proceso de objetivación participante. Por tanto, la cuestión de la reflexividad de la antropología es central, tanto en términos científicos como éticos.

Bourdieu destaca algunos tipos de reflexividad que operan y han operado en la antropología, en especial en sus descripciones etnográficas. Quizá la reflexividad más problemática por perniciosa es la "egológica" de la fenomenología (Bourdieu, 2003: 281), es decir, una reflexividad que se basa en una creencia sobre la naturaleza de nuestra objetivación de la realidad. Debo agregar que en tanto esta re- flexividad se basa en una creencia ontológica, la antropología y sus métodos se convierten en un medio justificado por un fin. El fin podría ser evangélico, como en el Instituto Lingüístico de Verano, pero también podría ser la antropología como una manera de hacer política desde las instituciones académicas. Otro tipo de reflexividad antigua, pero común entre los experimentos etnográficos posmodernos preocupados por el problema de la representación, es la idea de que los estudios de "los otros" son una forma para conocerse mejor uno mismo. En los encuentros con "los otros" nos descubrimos a nosotros mismos. ${ }^{1}$ Bourdieu describe esta reflexividad como narcisista. Habrá que advertir que el

\footnotetext{
${ }^{1}$ Véase Polier y Roseberry (1989) para una crítica excelente.
} 
relativismo en reflexividad egológica, sobre todo en versiones ontológicas, casi nunca es reflexivo y el relativismo en reflexividad narcisista no es necesariamente reflexivo. Si el relativismo no es reflexivo, entonces el punto de vista del observador es de alguna manera propuesto o supuesto como superior, es el punto de vista de un sujeto epistemológico, o el punto de vista de Dios, o quizá un punto de vista en el que el etnocentrismo se ha vuelto egocentrismo, a menudo como miembro de una clase social o un grupo de género dominante. Cabe hacer notar que en los trabajos de este número de Desacatos hay dos trabajos sobre aspectos de ética y antropología y luego dos comentarios críticos y reflexivos para cada uno. Pero aun cuando todos los autores están de acuerdo en establecer los factores que limitan o moderan el relativismo, sólo Esteban Ordiano Hernández hace explícita la necesidad de que el relativismo moderado que estudian sea reflexivo.

De nuevo, la postura de Bourdieu es clara a este respecto. La objetivación participante no puede tener una reflexividad científica si no objetiva la pretensión del etnógrafo para objetivar las representaciones de la gente que estudia. La ética antropológica tampoco debe separarse de esta exigencia. Esta pretensión de objetivar es necesariamente parte de las relaciones de poder y por tanto tiene que ubicarse en tiempo histórico y espacio social. Es notable, por ejemplo, que José Sánchez Jiménez trate de interpretar dos códigos de ética en relación con las reformas neoliberales en sus respectivos Estados nacionales. Éste es un punto importante, pero debe enfrentar la

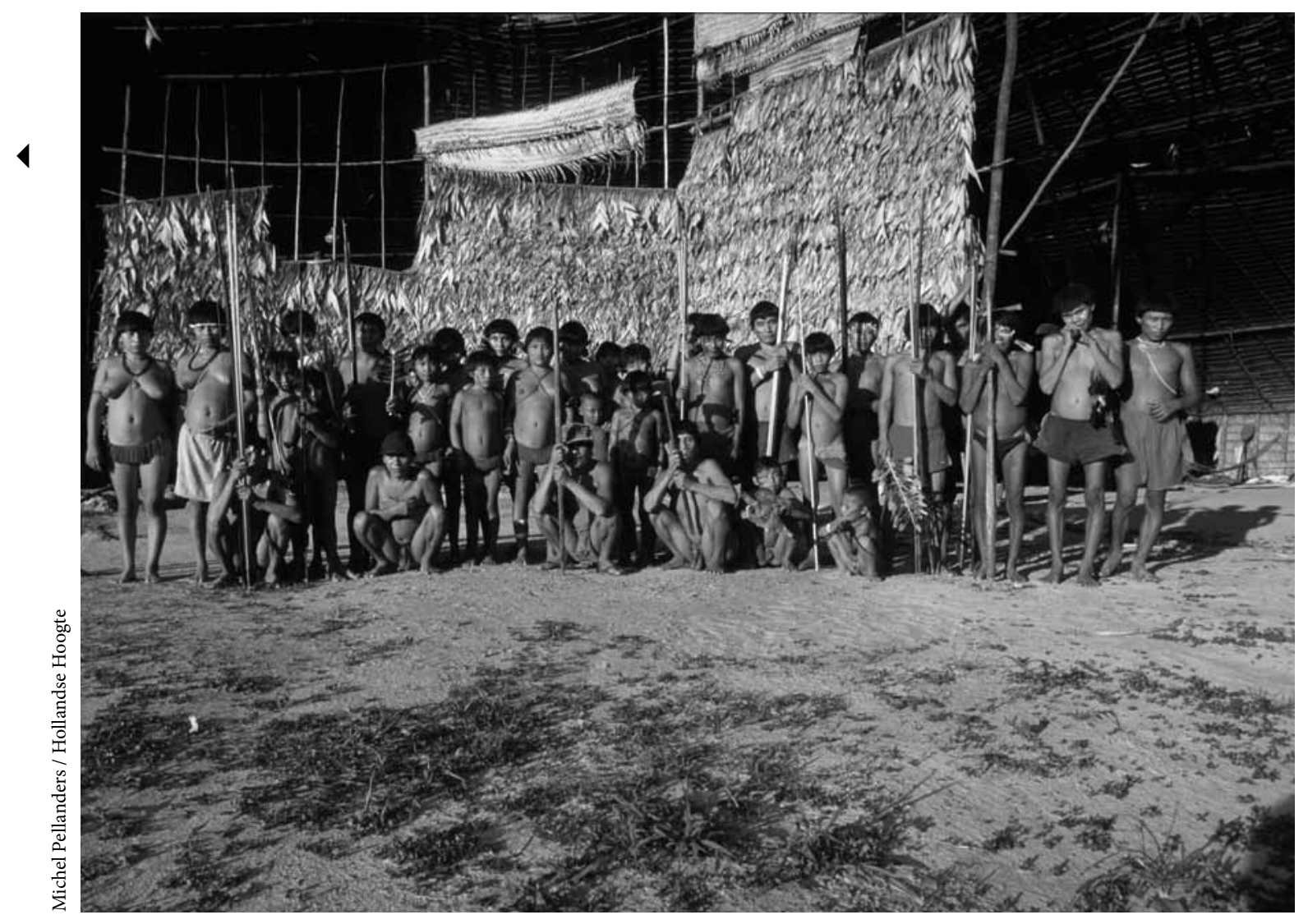

Indígenas yanomami, retrato de grupo. Tootobi, Roraima, Brasil, 1996. 
cuestión sobre cuándo logramos una contextualización adecuada en nuestras interpretaciones. Un ejemplo: Chile, uno de los países del estudio, se formó dentro de una tradición jurídica de ley positiva, mientras que al otro, la Unión Americana, corresponde otra tradición de ley casuística. ¿Podríamos encontrar estas dos tradiciones reflejadas en los dos códigos de ética? Esteban Ordiano Hernández explora las bases filosóficas de estas dos tradiciones en su análisis del trabajo de José Sánchez Jiménez, pero si vamos a tratar los códigos de ética antropológica como producciones culturales, y no como productos autónomos de los autores, sus luchas y sus experiencias, es menester mayor contexto histórico. En fin, es indispensable trascender los orígenes occidentales de la antropología. Esto nos obliga a fortalecer la reflexividad científica en nuestras prácticas de objetivación participante. Para lograrlo es necesario un relativismo moderado y reflexivo y también una orientación críticamente consciente de los riesgos de los etnocentrismos que emergen con formas de reflexividad egológicas-ontológicas y narcisísticas. Pero el reto mayor es más etnográfico e histórico que filosófico: la ubicación de nuestra objetivación participante en tiempo histórico y espacio social.

\section{Referencias bibliográficas}

Bourdieu, Pierre, 1977, Outline of a Theory of Practice, Universidad de Cambridge, Cambridge.

— , 2000, Pascalian Meditations, Universidad de Stanford, Stanford.

, 2003, "Participant Objectivation", en The Journal of the Royal Anthropological Institute, vol. 9, núm. 2, pp. 281-294.

, 2004, Science of Science and Reflexivity, Universidad de Chicago, Chicago.

Polier, Nicole y William Roseberry, 1989, “Tristes Tropes: Post-Modern Anthropologists Encounter the Other and Discover Themselves", en Economy and Society, vol. 18, núm. 2, pp. 245-264.

Rebel, Herman, 2004, "Después del siguiente genocidio: el modernismo reaccionario y el desafío postmoderno a la ética analítica. Recordando a Bill Roseberry”, en Relaciones. Estudios de Historia y Sociedad, vol. 25, núm. 98, pp. 147-210.

Roseberry, William, 1989, Anthropologies and Histories. Essays in Culture, History and Political Economy, Universidad de Rutgers, Nueva Jersey.

Roth-Seneff, Andrew, 2007, "Occidentalism and the Realism of Empire. Notes on the Critical Method of William Roseberry", en Critique of Anthropology, vol. 27, núm. 4, Sage, pp. 449-462.

Wittgenstein, Ludwig, 1993, "Remarks on Frazer's Golden Bough", en Ludwig Wittgenstein, Philosophical Occasions, 1912-1951, Hackett, Indianápolis, pp. 119-155. 